TRANS $\cdot$ núm. $24 \cdot 2020$

MISCELÁNEA $\cdot 419-434$

Ferréz llega a España en 2006 con la publicación de Manual práctico del odio, haciéndose representante de uno de los grandes sucesos literarios de Brasil en el siglo XXI, la nueva literatura marginal. Analizamos cómo afecta el proceso de traducción de su obra en la (re)significación literaria de esta estética y en la pérdida de su fuerza testimonial y política, que se revela mediante un lenguaje propio, jergal y coloquial como particularidad distintiva imposible de soslayar.

PALABRAS CLAVE: traducción literaria, literatura brasileña, nueva literatura marginal.

\title{
Ferréz y la nueva literatura marginal en España: una resistencia a la traducción
}

\author{
SOledAd SÁnChez FloReS \\ Universidad de Granada
}

\section{Ferréz and the New Marginal Literature in Spain: a resistance to translation}

Ferréz arrives in Spain in 2006 with the publication of the novel Practical Manual of Hatred, becoming a representative author of one of the great literary happenings of Brazil in the $21^{\text {st }}$ century, the new marginal literature. We analyse how the translation process of his work affects the literary (re)significance of this aesthetic and the loss of its testimonial and political force, which is revealed through its slangy, colloquial and original language, as a distinctive feature impossible to ignore.

KEY WORDS: literary translation, Brazilian literature, new marginal literature. 


\section{INTRODUCCIÓN}

El autor brasileño Ferréz llega a España en 2006 por primera y única vez hasta el momento con la novela Manual práctico del odio, editorial El Aleph (grupo Planeta). Ese mismo año se editaba en Italia, poco más tarde sería publicado en Francia (2009), en Argentina (2011) y en México (2012). La traducción de dicha novela en distintos países y lenguas viene de la mano de una creciente visibilidad nacional e internacional del autor, que se demuestra con su presencia en eventos de gran calado como la Feria del Libro de Fráncfort (2013) o el Salón del Libro de París (2015). A lo largo de las dos primeras décadas del siglo xxi asistimos a un escenario internacional que, desde diversos frentes, ha venido promocionando el surgimiento de una nueva literatura brasileña, no solo mediante eventos literarios de gran repercusión (Villarino Pardo, 2014a, 2014b, 2016), sino también con proyectos de antologías como la de la revista Granta (Baransi Feres y Silveira Brisolara, 2016) y con proyectos de incentivo económico como el Programa de Apoyo a la Traducción de la Biblioteca Nacional de Brasil (Rissardo y Magri, 2015). No obstante, dichos eventos han visibilizado un sector muy determinado de esa nueva literatura, abogando por autores que se insertan dentro de la llamada estética «cosmopolita» (Siskind, 2011; Resende, 2014; Schollhammer, 2016) y cuya recepción proyecta un estereotipo basado en una literatura «joven, blanca, urbana y de clase media» como describía el diario El país (Ballesteros, 2014) tras el evento en Fráncfort. La presencia de muy pocos representantes de esta estética marginal en eventos internacionales fue criticada por diferentes medios de comunicación donde se señalaba a Ferréz o a Paulo Lins como excepciones de la periferia (Souto Salom, 2014). La invisibilidad internacional de la llamada literatura marginal contrasta con la atención que la crítica brasileña está depositando sobre esta nueva estética, que es estimada por muchos como una de las grandes novedades literarias del siglo xxi en Brasil (Peçanha, 2009; Buarque de Hollanda 2014; Resende, 2014).

Asistimos, por tanto, a un proceso de (re)significación literaria que no puede explicarse sin una fundamentación política y económica en la que es determinante la actuación de una serie de dispositivos de mediación, los llamados gatekeepers (Thompson, 2012; Marling, 2016; Gallego Cuiñas 2018 y 2020). Gallego Cuiñas analiza exhaustivamente el papel que estos mediadores ejercen en la circulación y configuración de la literatura latinoamericana del siglo xxI, esto es «en la percepción y formación del gusto; así como en los mecanismos de consagración», ocasionando muchas de las veces «más visibilidad —rédito simbólico y económico- que la venta de libros, lo que implica un modo de actuación oculta que influye en la (re)producción y recepción» literaria (2020:17). Estos dispositivos pueden venir de fuerzas locales o internacionales como las ferias literarias, ránquines de revistas, traductores, becas, talleres, agentes literarios, etc. No obstante, estos gatekeepers no actúan siempre de forma aislada, sino que arman toda una red de mediadores que operan de forma encadenada, dando lugar a un proceso afectivo - en un sentido deleuzianoque determina de forma directa el modo en que una «comunidad interpretativa» (Fish, 1982) se relaciona con la obra y el autor que reciben. En este proceso entendemos que no solo el producto literario padece una afección - (re) significación literaria a partir del proceso de traducción, publicación, promoción y crítica- sino que la propia comunidad interpretativa también es afectada, por ejemplo, mediante la modificación de su horizonte de expectativas. 
En los análisis que investigadores como Erica Peçanha (2009), Paulo Tonani (2013) y Lucia Tennina $(2015)^{1}$ realizan sobre la genealogía literaria de Ferréz y de la estética de la que se erige impulsor, la literatura marginal, puede verse un proceso de (re)significación en el que se van perdiendo algunos de los elementos estéticos que lo definían al comienzo de su carrera como escritor. Este proceso, al que Tennina dedica unas reflexiones muy reveladoras, parece responder a las demandas de una edición comercial que busca hacer del autor y su obra un producto accesible al consumidor; esto es, hay un cambio trascendental entre el Ferréz de Capão Pecado, primera novela de estética marginal que el autor publica por la pequeña editorial Labortexto, al Capão Pecado publicado por Objetiva tras el aumento de la visibilidad mediática del autor. Este análisis fundamentado por Tennina (2015) nos conduce a la hipótesis vertebradora del presente ensayo: la suposición de que la traducción de Manual práctico del odio da lugar a una transformación y vaciamiento de su sentido original, que se suma al que venía experimentando en su espacio nacional a través de su proceso de adaptación al gran mercado, y determina de manera crucial el horizonte de expectativas español sobre la noción de literatura marginal. Para demostrarlo recogeré algunas de las propuestas teóricas que han significado a esta nueva literatura en Brasily

\footnotetext{
I Mencionamos estas investigaciones por ser de los primeros análisis académicos que de manera exhaustiva detallan lo que se ha venido denominando como «literatura marginal» 0 «literatura periférica» brasileña del siglo xxI. No obstante, esto no excluye a otros investigadores que hayan trabajado el tema en forma de artículos científicos o en otros medios de comunicación, como demuestran los recientes monográficos coordinados por Alexandre Faria et al. Modos da margem (2015) o el dossier coordinado por Lucia Tennina y Erica Peçanha, Literatura y periferia (2016), donde se recopilan diversos artículos de investigadores que debaten sobre estas nuevas expresiones marginales.
}

que ven en el estilo narrativo - principalmente en los diálogos de los personajes, que recrean el habla jergal de la periferia paulista - uno de los elementos más importantes que definen la estética marginal; como caso de análisis tomamos la obra de Ferréz Manual práctico del odio, donde veremos la problemática que implica su traducción y la consecuente banalización con respecto a su significación estética original.

\section{NUEVA LITERATURA MARGINAL: LA LENGUA PERIFÉRICA COMO DISPOSITIVO POLÍTICO Y TESTIMONIAL}

El término «literatura marginal» ya había sido aplicado anteriormente para referirse a un tipo de literatura producida durante la época de la dictadura militar de los 70, que se gesta dentro de círculos de producción y divulgación alternativos al mercado editorial, como libros mimeografiados, muros, periódicos, camisetas, etc. En el siglo xxi esta denominación adquiere una nueva acepción literaria con obras como las de Paulo Lins y su mundialmente conocida Ciudad de Dios o, menos mediático, Ferréz con Capão Pecado. La denominación literatura marginal puede considerarse oficial a partir del año 2001 mediante el proyecto impulsado por Ferréz en la revista Caros Amigos, una antología de narrativas testimoniales de la periferia urbana que pretende desmitificar los casos de Paulo Lins y de Ferréz como excepciones literarias, esto es, demostrar la presencia de un potente movimiento literario al margen de la academia y de la sociedad de clase media urbana. Erica Peçanha analiza el surgimiento de esta literatura marginal como una marca estética o «etiqueta producto» que ya había funcionado en el caso de los escritores marginales de los 70, en tanto sirve como seña de posicionamiento político y cultural de los escritores (2009: 45). 
422 Como forma de distinguir las literatura marginales de los 70 y las nuevas literaturas marginales, Peçanha propone una terminología concreta: «literatura marginal dos escritores da periferia», que se refiere a aquellos textos producidos por escritores de la periferia y que se desmarca de la literatura marginal de los 70; y «nova geração de escritores marginais», que se referiría a todo ese conjunto de escritores que desde los años 2000 se apropian del término «marginal» para referirse a una estética concreta preconizada por Ferréz y por los otros autores participantes en la antología de Caros Amigos, que volverá a publicar dos tomos de literatura marginal en 2002 y 2004, siguiendo el modelo del publicado en 2001. A estas publicaciones se suma la compilación que en 2005 Ferréz hace de algunos autores aparecidos en los tres tomos anteriores en un libro introducido por su manifiesto «Terrorismo literario». Aunque los prólogos de las diferentes ediciones de Caros Amigos pueden considerarse una suerte de manifiesto, es en «Terrorismo literario» donde se describe de forma más exhaustiva y esclarecedora cuáles son las características y objetivos principales de esta nueva estética marginal.

Una de las características principales que el manifiesto pone de relieve de esta literatura marginal es su existencia como literatura política, en el sentido en que Rancière lo define (2011), esto es, una literatura que es política no por hacer apología de un determinado partido político, sino en tanto que interviene «en la relación entre prácticas, entre formas de visibilidad y modos de decir que recortan uno o varios mundo comunes», en el recorte de «los espacios y los tiempos, de lo visible y lo invisible, de la palabra y el ruido» (2011: 17). Es cierto que vemos en esta literatura un activismo político cuyo objetivo es la mejora de las condiciones de vida en la perife- ria urbana: «Literatura de rua com sentido, sim, com un princípio, sim, e com um ideal, sim, trazer melhoras para o povo que constrói esse país mas não recebe sua parte» (Ferréz, 2005: 10). No obstante, esta literatura sería política debido a aquello que Rancière denomina «reparto de lo sensible», es decir, en esta literatura el poder de la palabra pasa a aquellos que antes no la tenían y se hace oír aquello que antes era considerado ruido, mediante una narrativa testimonial que alza las voces marginadas e invisibilizadas dentro de la sociedad y del propio canon literario. Afirma Ferréz en su «Terrorismo literario»: «Não somos o retrato, pelo contrário, mudamos o foco e tiramos nós mesmo a nossa foto» (9); «a literatura marginal se faz presente para representar a cultura de um povo, composto de minorias, mas em seu todo uma maioria» (9); «Estamos na rua, loco, estamos na favela, no campo, no bar, nos viadutos, e somos marginais mas antes somos literatura [...]» (10). De este modo, la representación de lo marginal se desmarca de las literaturas de la tradición brasileña como los regionalismos o brutalismos, que habían convertido a sujetos marginales en objetos literarios que eran narrados desde lugares de enunciación externos a esa realidad periférica; y toma como uno de sus objetivos fundamentales la lucha por el poder de la verdad, es decir, la apropiación de lo marginal a través de una narrativa testimonial.

A la vez que vindican una voz y una mejora social, también tienen como uno de sus principales propósitos hacerse un lugar dentro del espacio literario: «Jogando contra a massificação que domina e aliena cada vez mais os assim chamados por eles de "excluidos sociais" e para nos certificar de que o povo da periferia/favela/geto tenha sua colocação na história, e que não fique mais quinhentos anos jogado no limbo cultural» (Ferréz, 2005: 11). Esta penetración en la histo- 
ria cultural y literaria explicaría la publicación como forma de permanencia, es decir, no es una literatura que surge ahora, sino una literatura que ha estado viva durante mucho tiempo, pero se ha transmitido oralmente dentro del espacio de la periferia, lo demuestra la importancia que cobra el slam como poética propia de los saraus de la periferia urbana (Tennina 2015) ${ }^{2}$. No es casualidad que Ferréz haga en su «Terrorismo literario» un especial énfasis en el paso de la oralidad a la escritura: «Prus aliados o banquete está servido, pode degustar, porque esse tipo de literatura viveu muito na rua e por fim está aquí no livro» (12). La literatura marginal no ha surgido como novedad del siglo xxi, lo que realmente ha cambiado es la forma de circulación y de visibilización de esa literatura, en definitiva ese «reparto de lo sensible» del que habla Rancière (2011).

El estilo, marcado por vocabulario y expresiones coloquiales, vulgares y del gueto, viene determinado por una cultura propia y diferente de la académica, tornándose una de sus característica principal: «Mas alguns dizem que sua principal característica é a linguagem, é o jeito como falamos, como contamos a história, bom, isso fica para os estudiosos, o que a gente faz é tentar explicar» (Ferréz, 2005: 13). Ferréz reivindica como característica original que la literatura marginal sea representante de unas raíces estéticas propias del pueblo que hasta ahora habían sido olvidadas, raíces que críticos como Peçanha

2 Tennina (2015) hace un análisis de los saraus (que podríamos traducir literalmente como sarao en español) como espacio de emergencia literaria que, si bien ya existía anteriormente, es con el cambio de siglo cuando crece y se multiplica por diferentes barrios periféricos de ciudades como São Paulo o Rio de Janeiro: «Los saraus son centrales en la profundización de la producción de la literatura marginal de la periferia. Son, en palabras de Allan da Rosa, «el alma creativa del movimiento», es decir, que funcionan como una especie de taller literario informal de declamación de textos donde conviven todos los lectores, los poetas y escritores de las regiones alejadas del centro» (22).
(2009), Tonani (2013) o Buarque de Hollanda 423 (2014) identifican en gran medida con el rap y el hip-hop. Esto conllevaría a su vez una cuestión de calidad literaria a la que el próprio Ferréz alude: «Quem inventou o barato não separou entre literatura boa/feita com caneta de ouro e literatura ruim/escrita com carvão, a regra é só uma, mostrar as caras. Não somos o retrato, pelo contrário, mudamos o foco e tiramos nós mesmo a nossa foto» (2005: 9). Es decir, para Ferréz lo importante no es conseguir una literatura buena o mala, sino hacer leer, testimoniar una nueva cultura, visibilizarla y hacerla permanecer, para así conseguir que aquello que viene siendo juzgado como «literatura menor» sea visibilizado como una «literatura mayor»: «Hoje não somos uma literatura menor, nem nos deixemos tachar assim, somos una literatura maior, feita por maiorias, numa linguagem maior, pois temos as raízes e as mantemos» (13). Con estas apreciaciones Ferréz parece apelar al propio concepto de Deleuze y Guattari, «literatura menor» (1978), ya no solo por acudir al ejemplo de Kafka -que también usan Deleuze y Guattari- como autor que desde una «literatura menor» logra insertarse dentro del canon y cambiar el orden estético del momento, sino por su aproximación al concepto de «literatura menor» de una forma similar a la que hacen Deleuze y Guattari:

Las tres características de la literatura menor son la desterritorialización de la lengua, la articulación de lo individual en lo inmediato político, el dispositivo colectivo de enunciación. Lo que equivale a decir que «menor» no califica ya a ciertas literaturas, sino las condiciones revolucionarias de cualquier literatura en el seno de la llamada mayor (o establecida) (1978: 31)

Para Ferréz el lenguaje de la literatura marginal es el propio de la periferia, un lenguaje jergal, coloquial, con un fuerte componente de rap, 
424 que hace de su literatura menor una revolución al adaptarse a un formato (de la literatura oral a la literatura escrita) y circulación (mercado editorial) normalmente asociados a la literatura mayor, aquella aceptada por los medios de comunicación y por la academia. No es de extrañar que Ferréz comience el manifiesto apelando a la palabra y a la escritura como revolución: «[...] agora a gente fala, agora a gente canta, e na moral agora a gente escreve» (2005: 9). Y añade más adelante:

Jogando contra a massificação que domina e aliena cada vez mais os assim chamados por eles de «excluídos sociais» e para nos certificar de que o povo da periferia/favela/gueto tenha sua colocação na história, e que não fique mais quinhentos anos jogando no limbo cultural de um país que tem nojo de sua própria cultura, a literatura marginal se faz presente para representar a cultura de um povo, composto de minorías, mas em seu todo uma maioria.

E temos muito a proteger e a mostrar, temos nosso próprio vocabulario que é mjuito precioso, principalmente num páis colonizado até os días de hoje, onde a maioria não tem representatividade cultural e social [...] Mas estamos na área, e já somos varios, estamos lutando pelo espaço para que no futuro os autores do gueto sejam também lembrados e eternizados, mostramos as varias faces da caneta que se faz presente na favela, e para representar o grito do verdadeiro povo brasileiro. (2005: 13)

Ferréz entiende la lengua como un elemento de identidad de la periferia y una suerte de «máquina de expresión», en el sentido en que lo entienden Deleuze y Guattari cuando definen la literatura marginal como aquella capaz de «instaurar desde dentro un ejercicio menor de una lengua incluso mayor», de forma que la literatura se convierta en una «máquina colec- tiva de expresión» y adquiera «la aptitud para tratar, para arrastrar los contenidos» (1978: 32). El intento por sistematizar en la escritura una literatura hasta el momento eminentemente oral ya implica un acto de desterritorialización y una reterritorialización del portugués brasileño escrito. Esto conlleva un problema directo en el proceso de traducción: ¿cómo mantener el habla jergal de esta literatura de la periferia urbana brasileña en un español escrito?, ¿cómo mantener la fuerza expresiva y la guerra que late en su propia escritura?

\section{CASO FERRÉZ: UNA RESISTENCIA AL MERCADO, UNA RESISTENCIA A LA TRADUCCIÓN}

Ferréz ya era conocido en Capão Redondo por haber fundado junto a otros vecinos un grupo denominado «Movimento cultural 1daSul» con objetivos culturales y sociales que, mediante actos benéficos, como creación de bibliotecas dentro de la favela, promovían mejoras para el barrio. A partir de la publicación de Capão Pecado cobra rápida atención mediática, no solo por la promoción de ciertos medios de comunicación como la Folha de S. Paulo (Peçanha, 2009), sino que también encontramos una promoción mediática en las citas y firmas de raperos de gran visibilidad nacional, como Mano Brown, que participan como una suerte de «coautores» del libro Capão Pecado ${ }^{3}$. Tras dos reediciones en la pequeña editorial Labortexto, que también se había encargado de la publicación de la revista Caros Amigos, la gran editora Objetiva compra

\footnotetext{
3 Como indicaré más adelante, Capão Pecado se concibe como una novela particular debido a su carácter de obra literaria colectiva: una de las características más evidentes de esta colectividad es que cada una de las cinco partes en las que se divide el libro está inaugurada por un texto perteneciente a algún rapero nacional.
} 
los derechos de su segunda novela en 2003, Manual prático do ódio, y en 2005 se hace con los derechos para una segunda edición de $\mathrm{Ca}$ pão Pecado. Será a partir de su paso a esta nueva editorial cuando Manual prático do ódio comience a ser exportado internacionalmente. Tanto Peçanha (2009) como Tennina (2015) coinciden en señalar estos años como una etapa de transformación del autor y de la propia estética del libro Capão Pecado, sobre todo a partir de la compra de Objetiva, cuando experimenta una metamorfosis como proceso de adaptación al gran mercado; diferencia que se verá acrecentada en Manual prático do ódio.

Tennina plantea estas características atravesadas por dos claves interpretativas que permean la obra del autor y que conforman su propia estética. Por un lado, la obra pretende «desestabilizar y reactualizar la distinción entre ficción y no ficción» al tiempo que, por otro lado, articula «una propuesta singular del estatuto de lo real» (2015: 268). Es decir, la imposibilidad de representar la realidad periférica obliga a Ferréz a adaptarla ficcionalmente mediante diversas formas testimoniales como forma de legitimación de esa realidad que representa y que pone en jaque el «pacto de lectura», de modo que el lector no sabe cómo leer — documento o literatura - la narración que se le presenta (2015: 249). Muy en relación con esta característica estaría el tratamiento que hace Ferréz de esa realidad, ya que se presentaría en su obra, según Tennina, dentro del «orden de lo indomable» o de lo «intempestivo», ${ }^{4}$ en tanto que «pone en crisis los límites de lo decible,

4 Tennina toma este término del crítico Ítalo Moriconi, cuya referencia es traída por la autora: «O real é o que nos traz a imagem bruta, não editada. Existe a imagem editada, predominante no fluxo cotidiano da cultura, e a imagem não-editada, que tem uma potência de intempestividade. Nesse sentido, o signo intempestivo hoje mais provavelmente estará do lado do real que do lado da ficção» $(2015,271)$ de lo escuchable y de lo inteligible» $(2015,271)$. Este tipo de realidad indomable — todo aquello que denota el espacio social y cultural de Capão Redondo-, supone una imposibilidad de representación por medio de la escritura, y esto es lo que llevaría, según Tennina, a crear un libro que va más allá de lo real y que incorpora la ficción y el simulacro como forma de representación de esa realidad a la que sobrepasa. Para ello Ferréz acude a una estrategia híbrida donde se combinan diferentes medios, lenguajes y formas narrativas que ayudan a armar el carácter documental. Así, encontramos fotografías sobre espacios y habitantes de la favela, muchas de ellas sin diálogo directo con el relato, aunque sirvan de fuente documental del espacio narrado; párrafos extensos sin puntos ni comas como forma de representar aquella realidad indómita que desborda al propio texto; abundancia de personajes secundarios que no se vinculan con la trama principal pero que sirven como vestigios de una «realidad no editada» que se hace presente; o el lenguaje, con vulgarismos, argots y expresiones propias de la comunidad, muchas asociadas al rap nacional, cuyo carácter connotativo hace imposible la traducción de la obra.

Manual prático do ódio se compone de doce capítulos que se presentan como sentencias o interrogaciones que parecen responderse a sí mismas, como si se tratase del título de doce lecciones didácticas que aludirían al propio carácter de «manual» pedagógico con que se presenta, y apelando en algunas ocasiones directamente a un tú victimizado al que parece educar en la práctica del odio; por ejemplo: «Meu nome é amor, meu sobrenome é vingança»; «Não dei minha lágrima para ninguém»; «Lembra a última vez em que foi feliz?», «A única certeza é a arma». Esa voz en primera persona que se presenta en los títulos no vuelve a aparecer a lo largo del texto, donde la historia está narrada 
426 por una voz omnisciente en tercera persona. El argumento gira en torno a las situaciones que viven los seis personajes principales, habitantes de una misma favela, que son guiados hacia un mismo objetivo, el dinero, que se convierte en motor de la historia, y que pretenden obtener mediante un asalto organizado a un banco. Esta narración se estructura de forma fragmentada, presentando por escenas a todos los personajes, sin que haya una distinción clara de cuáles son los principales y cuáles los secundarios, hasta que va llegando el asalto, que es el conector de los protagonistas. Los fragmentos parecen estructurarse como golpes de información - lo que nos recordaría a la intempestividad narrativa que detecta Tennina (2015) - , a partir de los que se describe a los personajes, sus acciones, sus relaciones, sus pensamientos y el espacio en el que se mueven, en aras de mostrar cómo la realidad específica de la periferia los moldea y dirige hacia el odio, la ambición, la violencia y el crimen. Más que la narración del asalto, lo interesante es la tensión que el autor produce hasta el desencadenamiento del asalto, donde se alcanza el cenit de la narración, como si ese fuese el objetivo último por el que había sido tensado todo el argumento anterior, y a partir del que se produce una coda final en la que se cuenta el trágico destino de los protagonistas. La necesidad de contar el totum de la realidad no editada (Tennina, 2015: 277) es lo que determina esa estructura fragmentada, que mediante largos párrafos llenos de comas y con pocos puntos, intenta representar una realidad connotada que escapa a las palabras; surge así un relato mal cohesionado como estrategia de representación de una realidad intraducible a la palabra escrita.

Para Erica Peçanha Manual prático do ódio presenta los mismos recursos que despertaron el interés del público por Ferréz en Capão Pecado: desde el estilo narrativo, el tema de la violencia y la pobreza, hasta aquellos aspectos sociológicos que envuelven el régimen de producción del autor, es decir, su voz como testimonio de una realidad que ha vivido (2009: 212). No obstante, hay ciertas características propias de la estética marginal que defendía en «Terrorismo literario» y cuya presencia en la primera edición de Capão Pecado hacían de esta obra prima un ejemplo capital de la nueva literatura marginal. Tennina (2015) defiende que algunas de estas características parecen perderse en el proceso de adaptación al gran mercado, lo cual podemos interpretar como una suerte de resistencia a la circulación a gran escala. Intuimos que esta resistencia se ve incrementada aún más en el momento de su traducción, por lo menos en lo que respecta a la versión española de El Aleph.

\section{Pérdida del carácter de colectividad}

Uno de los principales rasgos de la nueva literatura marginal es precisamente el carácter de obra colectiva, al que habíamos visto que hacían referencia Deleuze y Guattari en su consideración sobre una «literatura menor» (1978). Las obras de Ferréz, especialmente la primera de ellas, Capão Pecado, son ejemplo de ese carácter de obra colectiva donde el autor queda en un segundo plano en aras de protagonizar la voz de la periferia. Por ejemplo, en la primera edición de Capão Pecado el libro queda organizado en cinco partes que aglomeran 23 capítulos, y cada parte está introducida por un texto perteneciente a algún rapero, de forma que la autoría de la novela queda repartida en diferentes voces. No obstante, ese elemento colectivo se va perdiendo a medida que la obra es absorbida por el mercado, por lo que ya en la segunda edición disminuye 
el carácter colectivo de la obra y los raperos cobran menos protagonismo, de forma que si antes eran los raperos los que comentaban la obra en la cubierta del libro, ahora es la prensa la que lo hace: la contratapa presenta un resumen del argumento, referencias al autor y una crítica de Folha de S. Paulo. Esta colectividad, que hacía del libro un proyecto de la propia favela - o favelas, porque Capão Pecado puede entenderse como una analogía que abraza y referencia, no solo a Capão Redondo sino a todas las favelas como espacio marginal - a través de la voz de varios raperos marginales, desaparece totalmente en Manual prático do ódio.

La introducción de la edición española y brasileña de Manual práctico del odio es una dedicatoria en primera persona destinada a los enemigos: «A los que conspiraron y alentaron $\mathrm{mi}$ caída, nada más justo que presentar el tercer filo, el Manual práctico del odio está ahí, reforzando la derrota de los que atentaron contra mí y contra los míos» (2006: n.p). En portugués: «Aos que conspiraram e torceram pela minha queda, nada mais justo que apresentar a terceira lâmina. $O$ Manual prático do ódio está aí, fortificando a derrota dos que atentaram contra mim e os meus» (2003: n.p). En un análisis de la traducción española, podríamos entender una amenaza personal del autor hacía aquellos que atentaron sobre su persona y a Manual práctico del odio como un arma de lucha individual. La falta de un horizonte referencial no nos da cuenta de la alusión colectiva que adquiere esa dedicatoria, que se refiere al título del tercer álbum de un reconocido cantautor brasileño, Zé Ramalho, que reivindica con la letra de la canción homónima el carácter de arma de guerra que tiene su tercer álbum —o terceira lâmina en portugués, donde «lâmina» adquiere el sentido de «filo que corta»Según la música de Zé Ramalho, esta arma se presenta dulce y fácilmente digerible al ser una melodía, pero se adentra en las cabezas y devora las consciencias de aquellos que provocan el sufrimiento y el hambre del pueblo 5 . Aunque el traductor ponga en el pie de página la referencia al cantante, no se explica el propósito de la cita, perdiendo de este modo la fuerza y el significado del mensaje, y quedando simplemente como una amenaza que podría ser interpretada a nivel personal y no con el carácter colectivo al que apela la música de Zé Ramalho.

\section{Construcción de autor}

Muy en relación con la descolectivización está la transformación que el autor experimenta desde el primer libro en Labortexto hasta la traducción en español de Manual práctico del odio. En la primera edición de Capão Pecado son recurrentes las fotografías documentales de la favela entre las que se puede identificar a Ferréz junto a otros vecinos de la comunidad, de esta forma se pone en primer plano el escenario urbano y sus habitantes como verdaderos protagonistas de la novela. Como observa Tennina, ya en la segunda edición se percibe un primer paso hacia la individualización y subjetivación del autor, que se manifiesta de forma evidente en la desaparición del «Prefacio» que en la primera edición

5 El tercer filo/ Es aquel que hiere/ que se hace más tranquilo/ con el hambre del pueblo/ con pedazos de vida/ como la dura semilla/ que se prende en el fuego/ de toda la multitud/ que considero mucho más efectiva/ que piedras en la mano. / De los que viven callados/ colgados en el tiempo/olvidando los momentos/ en el fondo del pozo/ en la garganta del foso/ en la voz de un cantautor. / Y vendrá como guerra/ el tercer mensaje/ en la cabeza del hombre/ aflicción y coraje/ él piensa en la fiera / que comienza a devorar/ creo que los años/ se van a pasar. / Con aquella certeza/ que tendremos en los ojos/ nuevamente la idea/ de salir del pozo/ de la garganta del foso/ de la voz de un cantautor. (Traducción propia) 
428 colocaba como protagonista el espacio urbano de la favela; y en su lugar aparece una «Nota do autor para a nova edição», donde prima la primera persona y su experiencia como escritor de la favela, anulándose así las referencias al círculo literario en el que se movía y haciendo de él una excepción dentro de esa periferia social (2015: 240). En concordancia con la autora, observamos cómo Ferréz experimenta a partir de esta segunda edición un doble proceso performativo: por un lado, se erige «como la voz autorizada para testimoniar sobre las experiencias periféricas» y por otro lado, «como un escritor preocupado por el cultivo de su escritura» (2015: 240).

En lo que respecta a la edición de Manual práctico del odio en España, la presentación que se hace del autor es prácticamente igual a la de Objetiva y, del mismo modo que ocurría en la segunda edición de Capão Pecado, se afianza la figura de escritor surgido de forma excepcional en la periferia: en la solapa de la edición de El Aleph se construye una biografía basada en los hitos literarios del autor, como una excepción que consigue por medio de la superación personal al acceder al medio intelectual; se destacan sus orígenes humildes y su dificultad por formarse e ir a la escuela dentro de ese entorno, así como sus diferentes trabajos como panadero, pintor de obra o vendedor de camisetas; es presentado como un autor íntimamente ligado al movimiento del hip-hop y se destaca su objetivo de reivindicar «la voz y la dignidad de los habitantes de las periferias de las grandes ciudades brasileñas». Una característica peculiar de la edición de El Aleph que pone distancia con la edición de Objetiva es que en la tapa del libro, debajo del título se coloca una cita referida al autor: «El nuevo trovador de los suburbios de São Paulo». A falta de un horizonte referencial capaz de connotar la carga política del libro, se señala al autor como trovador, en lugar de como escritor o poeta. Esto último es interesante porque, como explica Tennina, en el contexto periférico es normal que a los slamer se los incluya dentro de la categoría de poetas como forma de legitimación de su arte (2015: 47). En ese sentido, la creación del concepto «trovador» lejos de solucionar el problema semántico, añade una nueva vuelta interpretativa, en tanto parece aludir a una actividad no canonizada o no poética que es propia de la periferia. Sobre este dato tenemos que aclarar que, si bien Ferréz ha sido slamer, no ha sido esta su actividad principal; podríamos considerar la cita como clave referencial si se aludiera directamente, en todo caso, a Ferréz como slamer, ya que sería una manera de vincular al autor con un tipo particular de literatura marginal. No obstante, el hecho de utilizar el término «trovador» crea una ambigüedad referencial y da lugar a una (re)significación del autor en términos de escritor fuera del canon.

\section{Pérdida del documento testimonial: fotografía, estilo narrativo y lenguaje}

Veíamos cómo el carácter documental y testimonial de la estética marginal está íntimamente relacionado con el juego ficción/realidad y con el tratamiento de una realidad intempestiva. Si bien permanecen ciertos rasgos, como el estilo narrativo con amplios párrafos saturados de información y estructurados por comas, hay otros rasgos que experimentan una profunda transformación desde la primera edición de Capão Pecado hasta la publicación de Manual práctico del odio por El Aleph.

Tennina nos indicaba que uno de los cambios más perceptibles es la temprana desaparición 
del documento fotográfico desde la publicación de Capão Pecado por Objetiva, que tan presente estaba en la primera edición de Labortexto, con imágenes a color y blanco y negro que ponían formas y caras a los espacios y personas de la propia comunidad de Capão Redondo (2015: 236). En la segunda edición, las fotografías desparecen tanto de la tapa como del interior del libro, eliminando cualquier imagen documental, tan solo dando espacio a la escritura (2015: 239). Esta desaparición continuará también en Manual práctico del odio, tanto en Objetiva como en El Aleph. Las portadas también sufrirán un cambio trascendental. Mientras que la edición brasileña de Objetiva está conformada por una fotografía de un niño con alas de ángel en medio de un espacio afavelado, en la edición de El Aleph se elimina cualquier alusión a un espacio real, no se muestra ningún documento fotográfico. En su lugar, el diseño de la portada está conformado por el nombre del autor en grandes grafías azules, secundado del título en blanco, que resaltan sobre un fondo negro. Además de la cita antes mencionada — «El nuevo trovador de los suburbios de São Paulo»-y del nombre de la editorial, sobresale la imagen de una pistola empuñada por una mano. De este modo, mientras que en la edición de Objetiva se colocaba el foco sobre los habitantes de la favela como víctimas de la violencia — niño con alas sobre un espacio afavelado-, la edición española de El Aleph pierde toda esa carga connotativa y deposita el foco sobre la violencia, acentuando el estereotipo brasileño de la violencia armada; una realidad extraña - exótica-dentro del horizonte referencial español, en la que la violencia con arma de fuego es una excepción, mientras que en ciudades como Rio de Janeiro y São Paulo forma parte de la cotidianidad. Poner el foco en el arma, y no en las víctimas inocentes
— como sí ocurría en la edición de Objetiva-, descarga de fuerza crítica a la portada del libro de El Aleph, que se queda con la parte más superficial, el arma.

Por otro lado, como hemos visto, el lenguaje es una de las estrategias más características de esta estética marginal, no sólo como elemento testimonial sino por el carácter político que conlleva su escritura y el proceso de reterritorialización que se origina como consecuencia (Deleuze y Guattati, 1978): se produce una desterritorialización de la literatura marginal que se circunscribía a un espacio periférico concreto y a un tipo de literatura eminentemente oral; y reterritorializa la noción de «literatura brasileña del siglo xxI» al incluir una nueva voz prácticamente sin precedentes, la voz de la periferia; $y$ al mismo tiempo también reterritorializa un nuevo espacio de producción y consumo, el mercado editorial, respecto al que se había mantenido ajeno hasta el momento.

Si en la versión brasileña de Manual prático do ódio (Objetiva) se perdía la fotografía como elemento testimonial que tan presente estaba en las ediciones de la novela anterior, la articulación del lenguaje marginal como elemento testimonial paliaba en cierta medida la pérdida documental de aquellas fotografías. No obstante, en su paso a la edición española el proceso de traducción hace que el poder de esa estrategia lingüística testimonial se vacíe: si bien es cierto que la traducción acude a expresiones populares, palabrotas o coloquialismos, se pierden formas de pronunciación propias del portugués periférico de São Paulo; y la tendencia a estandarizar el lenguaje implica la pérdida de toda una serie de connotaciones que dan fuerza política al texto en la versión brasileña. Vamos a verlo con el ejemplo de un extracto en ambas versiones, portugués (Objetiva) y español (El Aleph): 
-E aí, Nego Duda? Porra, nem te vi, tudo pela ordí?

-Mais o menos, Régis, oh!, tô precisando de uma dica sua, oh, e isso vai me dá mó visão.

-Diga então jão, se puder eu ajudo.

-Vamo pro canto, chega aí.

[...]

-O barato é o seguinte, tô com um esquema bom, pra fazer um maluco.

-Quem que é? -perguntou Régis colocando a mão dentro da cintura novamente, com o temor de Nego Duda falar que era ele, se fosse esse o caso, quem puxasse primeiro fritaria o outro.

-Você num conhece, mora longe.

-Sério? -disse Régis tirando a mão da cintura novamente.

-Mas num é isso que interessa, o que pega é o seguinte, o maluco quer dar cinco pau pra o outro ir pro inferno, só que quero saber com você como vou fazer isso?

-Fazendo, porra! -respondeu Régis com ironia.

-Cê tá me zuando, eu sei, mas num sei se pega alguma coisa, o maluco mora lá no Brás, pode ser encrenca, num conheço a área, truta.

-Peraí, deixa eu pensar... Faz assim, ó, dá um psicológico no cara, nesses caso, força num é nada, você tem que usar a sapiência. (2003: 34)
-¿Qué hay, Nego Duda? Coño, no te había visto, ¿estás bien?

-Más o menos, Régis, mira: necesito que me des una pista, oye, y tal vez así pueda ver más claro.

-Habla, pues, te ayudaré en lo que pueda.

-Vamos a ese rincón, acércate.

[...]

-El asunto es el siguiente: ando con un buen plan para cargarme a un tipo.

- ¿Y quién es? -preguntó Régis llevando de nuevo su mando a la cintura, con el temor de que Nego Duda dijese que era él y, si fuese así, el más rápido acabaría con el otro.

-Tú no lo conoces, vive lejos de aquí.

-¿En serio? -dijo Régis retirando de nuevo la mano de la cintura.

-Pero no es eso lo que interesa, lo que importa es que me quieren dar cinco talegos para mandarlo al infierno, pero me gustaría que me dijeses cómo puedo hacerlo.

-¡Haciéndolo, joder! -respondió Régis con ironía.

-Te estás quedando conmigo, lo sé, pero no sé si me entiendes bien; el tío vive en Brás, puede haber follón, no conozco la zona, compi.

-Espera, déjame que piense... Lo que tienes que hacer es jugar con la psicología del tío. En esos casos, la fuerza no sirve de nada, tienes que usar la astucia. (2006: 32)
Tan solo en esta breve conversación entre dos de los personajes principales comprobamos diferencias fundamentales en la traducción. No obstante, expondré solamente ciertos ejemplos cuya traducción modifica de manera sustancial el sentido original del texto: deformaciones fonológicas y gramaticales, interpelaciones populares o jergales, formas verbales y expresiones populares y palabras malsonantes.

\section{I.Deformaciones fonológicas y gramaticales}

En el habla jergal paulista se observan formas de pronunciación propias que modifican la escritura correcta de la palabra: en «ordi» en vez de «orden»; o en «num» en vez de «não»; o «cê» como aféresis de «você». Asimismo, también vemos la pérdida de fonemas y combinación de dos palabras en una sola: «peraí», en vez de «espera aí». Lo interesante de estas deformaciones es que no son indicadas entre 
comillas por el escritor sino que inundan todo el texto mediante el diálogo de los personajes, haciendo más real la presencia de esas voces periféricas en el texto, como si al quitar las comillas eliminase también su consideración como palabras erróneas y las naturalizara como propias del portugués escrito. Si bien es cierto que en la versión española tampoco hay comillas, la mayor parte de estas palabras son traducidas de forma neutral, por lo que se pierde toda la connotación jergal; por ejemplo: «Peraí, deixa eu pensar...» es traducido por «Espera, déjame que piense...»; es decir, no se produce ninguna deformación fonológica que sea asimilable con un habla periférica española. Una solución a ese caso concreto sería acudir a alternativas como «Perahí, deja que piense...» o «Parahí, déjame pensar» o incluso «paraí, déjame que piense»: casos propios de variedades del español donde hay una aféresis al comienzo de la palabra y la unión sonora de «pera» con «ahí»; la otra opción propuesta sería la sustitución de espera por «para» y su combinación con «ahí»; y la última opción iría un paso más allá al introducir un error ortográfico, que si bien no hay en la versión original, sí iría en la tónica del texto en portugués, donde es común observar errores ortográficos como «cinco pau» — cinco palo- o «nesses caso» - en esos caso_-, donde se observa una falta de concordancia numérica entre determinante y sustantivo. Con estas alternativas no solo se daría una mayor velocidad propia de un habla espontánea, sino que se mantendrían aféresis y uniones sonoras que, aunque no sean correctas a nivel escrito, son más fieles a un habla periférica que podría recordarnos, por ejemplo, al dialecto andaluz como variedad periférica respecto al español estándar.

\section{Interpelaciones populares o jergales}

Interpelaciones como «jão» o «ó» son eliminadas en la traducción: en el primer caso «Diga então jão, se puder eu ajudo», es traducido como «Habla, pues, te ayudaré en lo que pueda»; mientras que «Faz assim, ó, dá um psicológico no cara» es traducido por «Lo que tienes que hacer es jugar con la psicología del tío». Como vemos, hay una desaparición de elementos que dan espontaneidad al discurso hablado: el primero de ellos es un apelativo que aunque viene del nombre «João», no se refiere necesariamente a un nombre concreto de persona sino a cualquier amigo próximo, que es tratado con la confianza como para ser llamado así; en español sí hay un habla popular donde se admita el nombre «Juan» como apelativo para cualquier hombre independientemente de su nombre, aunque no esté aceptado dentro de un español estándar; pero como alternativa podría acudirse también a otras opciones fácilmente asimilables por cualquier lector español como «tío». En el caso de la interjección «ó», se trata de una forma popular de ciertas zonas de Brasil que podría ser traducida de una forma estandarizada por «escucha», «oye» o «mira», no obstante también podría ser traducido por «cucha»-aféresis de «escucha»-, y aunque no correspondería con el significado literal de la palabra, sí conservaría una connotación que la aproxima más al diálogo original.

\section{Formas verbales}

La forma verbal tiene un factor determinante en la espontaneidad que adquiere el discurso hablado, por ejemplo: el futuro de subjuntivo, extremamente normalizado en el habla coloquial brasileña — «diga então, jão, se 
432 puder eu ajudo»- es traducido por un futuro simple en español — «habla, pues, te ayudaré en lo que pueda»-, que no solo da lentitud a la frase sino que la hace propia de un diálogo poco natural. Esta artificialidad aumenta al usar la conjunción «pues» como traducción de «então» — «entones» en español—, cuando haber mantenido la traducción literal «entonces» en este caso, que también es una expresión normalizada en español, habría sido más exacto. Aunque se intenta mantener el uso del futuro, el sentido de inmediatez que tiene el futuro de subjuntivo en portugués no la tiene el futuro simple español, por lo que en este caso concreto es mejor sacrificar la forma verbal en aras de mantener el sentido, por ejemplo, usando un presente simple: «Habla entonces, tío, que te ayudo en lo que pueda». En la propuesta que hacemos añadimos la interpelación «tío» —que habíamos visto que desaparecía al eliminar «jão»—; añadimos la conjunción «que» con función de coordinativa —muy común en el habla cotidiana-; y, por último, cambiamos el futuro de subjuntivo por el presente simple para poder mantener la inmediatez de la sentencia.

\section{Expresiones populares y palabras malsonantes}

Palabras como «maluco» — «loco» traducido literalmente, aunque en este caso «fazer um maluco» adquiera el sentido de «matar a alguien»-, pierden su carácter jergal al ser traducidas de forma estandarizada, sin ningún tipo de vinculación con el habla de la calle: la expresión «fazer um maluco» en la versión española podría traducirse como «cargarme a un tipo», que es la opción que toma El Aleph, pero mejoraría su coloquialidad si en vez de «tipo» se traduce como «tio», más común en el lenguaje popular. También ocurre lo mismo con la palabra «barato» — «O barato é o seguinte»-, que es traducido como «asunto» — «el asunto es el siguiente»—, una traducción literal a nivel semántico pero que de nuevo pierde su carácter habla popular: en el caso podría ser sustituida por «movida» — «la movida es la siguiente»-.

El carácter literal y estandarizado que domina en la traducción es, no obstante, combinado con ciertas palabras malsonantes — «joder, coño»—, expresiones populares — «cargarse a alguien»-, palabras coloquiales —«tío», «follón»-. Si bien esta es una opción probablemente tomada para dar un toque popular dentro de un español neutro, tiene como resultado un diálogo aún más desnaturalizado e impostado, en tanto dichas expresiones populares disuenan con respecto a la tónica estandarizada de la narración

\section{CONCLUSIONES}

Vistas todas estas modificaciones, comprobamos cómo el tratamiento de la realidad intempestiva y de los juegos entre realidad y ficción se debilitan cuantiosamente por la pérdida de rasgos testimoniales, como la fotografía o la descolectivización de la obra, íntimamente asociada a la estética del rap. Asimismo, con la traducción estandarizada se elimina una de las mejores estrategias de la estética marginal, perdiéndose su fuerza política y testimonial, que se ve incrementada por una descontextualización intrínseca a un proceso de traducción como este, donde el sujeto y objeto narrativos pertenecen a un espacio cultural, económico y social diferente al de un consumidor español de clase media (suponiendo que este sea el receptor normativo). Aunque se mantienen algunas estrategias 
que buscan reproducir el juego realidad/ficción, estas resultan pobres en comparación a la reproducción del lenguaje periférico. La pérdida de una voz periférica conlleva a su vez el acercamiento a propuestas que como las de Rubem Fonseca, máximo exponente de la estética brutalista (Bosi: 1975), narran la violencia urbana y al sujeto periférico desde una voz crítica que, sin embargo, se coloca desde un lugar de enunciación diferente, que puede ser testimonial, pero no de pertenecimiento. La literatura marginal se convierte, de este modo, en una pseudoestética de lo marginal en su paso a España, un vestigio temático, mera ambientación desreferenciada, que puede dar lugar a una interpretación estereotipada y exótica de la periferia marginal.

El análisis de la traducción de Manual práctico del odio de Ferréz es una prueba del impacto que tiene la traducción como gatekeeper, mediador del texto escrito y (re)significado de su valor y sentido original. A pesar de esta función determinante, la traducción no es la única responsable en el proceso de significación literaria. Recordemos que el propio Iser habla de la significación como el resultado de la interpretación que se lleva a cabo por medio de la «inferencia» o «conjeturas» realizadas por cada lector, y que le otorga un carácter ilimitado y variable en tanto que se actualiza — vuelve a significarse, se (re) significa - con cada acción interpretativa (2005: $40)$. Es decir, el proceso de lectura en un receptor español es radicalmente diferente al de un lector brasileño, y no sólo por el idioma, sino por todo el horizonte referencial que determina su interpretación: así, no es igual la lectura que hará un portugués de Brasil que de Portugal, ni un lector carioca o gaucho, ni aquel perteneciente a la periferia desde la que se enuncia el texto o de un barrio de clase alta; el lugar social, económico y espacial determinan de forma crucial el proceso de (re)significación del texto. Llegados al final de este breve ensayo, concluimos con una incógnita que abre el camino a nuevas investigaciones: ¿es la estética marginal realmente intraducible? Intuyo que la respuesta está en las futuras traducciones de nuevos autores y estéticas marginales que están por llegar, tal vez la dificultad no radica en esta nueva literatura periférica sino en la intraducibilidad del propio Ferréz.

\section{REFERENCIAS BIBLIOGRÁFICAS}

Ballesteros, Cecilia (2014): «Nueva literatura brasileña: joven, blanca, urbana y de clase media». El País, 18 de marzo <https://elpais.com/cultu$\mathrm{ra} / 2014 / 03 / 16 /$ actualidad/1395005272_200765. html>.

Baranski Feres, Lilia y Valeria Silveira Brisolara (2016): «A literatura brasileira em tradução: o caso do Programa de Apoio à Tradução e à Publicação de Autores Brasileiros no Exterior», Revista Digital do Programa de Pós-Graduação em Letras da PUCRS, 9, 144-154, doi: 10.15448/1984-4301.2016.s.22388.

Bosi, Alfredo (1975): O conto brasileiro contemporâneo, São Paulo: Cultrix.

Buarque de Hollanda, Heloisa (2014): «Crônica marginal», en Beatriz Resende (ed.) Possibilidades da nova escrita literária no Brasil, Rio de Janeiro: Editora Revan, 25-38.

Deleuze, Guilles y Felix Guattari (1978): Kafka. Por una literatura menor, trad. Jorge Aguilar Mora, México: Ediciones Era.

FARIA, Alexandre, João Camilo Penna, y Paulo Roberto Tonani do Patrocinio (2015): Modos da margem. Figurações da marginalidade na literatura brasileira, Rio de Janeiro: Aeroplano.

FerRÉz (2000): Capão pecado, São Paulo: Labortexto. FERRÉz (2003): Manual prático do ódio, São Paulo: Objetiva.

FERRÉz (2005): «Terrorismo literário», en Ferréz (ed.) Literatura marginal: talentos da escrita periférica, Rio de Janeiro: Agir, 9-14.

FERrÉz (2005): Capão pecado, São Paulo: Objetiva. FERRÉz (2006): Manual práctico del odio, trad, Mario Merlino. Barcelona: El Aleph. 
434 Fish, Stanley (1982): Is there a text in this class? The authority of interpretative communities, Massachusetts: Harvard University Press.

Gallego CuIÑAs, Ana (2018): «Claves para pensar las literaturas latinoamericanas del siglo xxı». Ínsula, 859-860, 2-4, < https://www.insula.es/revista/lanovisima-literatura-latinoamericana-2001-2015>.

Gallego CuIÑAs, Ana (2020): Las novelas argentinas del siglo 21: nuevos modos de producción, circulación y recepción, New York: Peter Lang.

IsER, Wolfgang (2005): Rutas de la interpretación, trad. Ricardo Rubio Ruiz, México: Fondo de Cultura Económica.

MARLIng, William (2016): Gatekeepers. The Emergence of World Literature and the 1960, Nueva York: Oxford University Press.

Peçanha, Erica (2009): Vozes marginais na literatura, Rio de Janeiro: Aeroplano.

RANCIÈRE, Jacques (2011): Politica de la literatura, trad. Marcelo G. Burello, Lucía Vogelfang y J.L. Caputo, Buenos Aires: Libros del Zorzal.

Resende, Beatriz (2014): Possibilidades da nova escrita literária no Brasil, Rio de Janeiro: Editora Revan.

RISSARDo, Agnes y Ieda Magri (2015): «A literatura brasileira no exterior: entrevista com Moema Salgado e Fábio Lima (FBN)». Z Cultural, <http://revistazcultural.pacc.ufrj.br/a-literatura-brasileira-noexterior-moema-salgado-e-fabio-lima-fbn>.

SchøllhammER, Karl Erik (2016): «La literatura brasileña contemporánea y su crítica», Cuadernos de Literatura, 20/40, 204-214, doi: 10.11144/Javeriana. cl20-40.lbcc.

Siskind, Mariano (2011): «Nuestras imposibilidades. La argentinidad de la literatura argentina y el cosmopolitismo de la literatura brasileña», en Mario Cámara, Lucía Tennina y Luciana di Leone (ed.), Experiencia, cuerpo y subjetividad: nuevas reflexiones, Buenos Aires: Santiago Arcos editor, 183-198.

Souto Salom, Julio (2014): «La literatura marginal periférica y el silencio de la crítica», Revista chilena de literatura, 88, 235-264, doi: 10.4067/S071822952014000300013.

Tennina, Lucía (2015): Literaturas del margen / Literaturas al margen, Tesis doctoral, Universidad de Buenos Aires.
Tennina, Lucía y Erica Peçanha do Nascimento (2016): Literatura e Periferia. Estudos de Literatura brasileira contemporânea, 49, doi: 10.1590/2316-4018491.

Thompson, John (2012): Merchants of Culture. The Publishing Business in the Twenty-First Century, Nueva York: Plume.

Tonani, Roberto (2013): Escritos à margem: a presença de escritores de periferia na cena literária contemporânea, Rio de Janeiro: 7Letras.

Villarino PARDo, Carmen (2014a): «As feiras internacionais do livro como espaço de diplomacia cultural», Brasil, 50, 134-154.

Villarino Pardo, Carmen (2014b): «Imagem e(m) exportação: exibição e negócio nas feiras internacionais do livro - o caso do Brasil», en Ricardo Barbena y Vinicius Carneira (ed) Das Luzes as soleiras: perspectivas críticas na literatura brasileira contemporânea, Porto Alegre: Luminara Editorial, 57-84. 